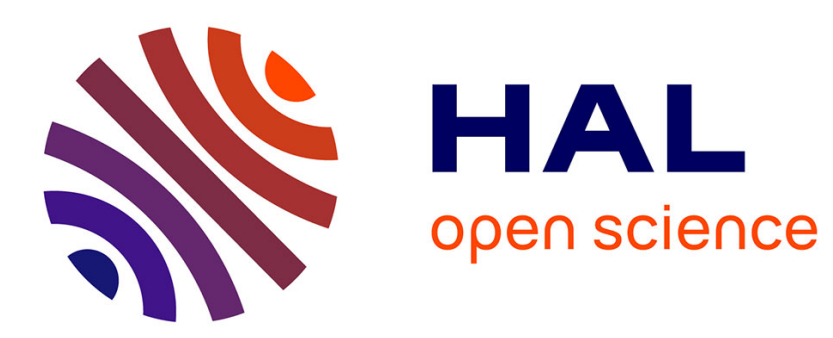

\title{
The Epstein-Barr virus (EBV) protein EB2 is an mRNA export factor essential for virus production
}

\author{
Alain Sergeant, Henri Gruffat, Evelyne Manet
}

\section{To cite this version:}

Alain Sergeant, Henri Gruffat, Evelyne Manet. The Epstein-Barr virus (EBV) protein EB2 is an mRNA export factor essential for virus production. Frontiers in Bioscience, 2008, 13. hal-01927979

\section{HAL Id: hal-01927979 \\ https://hal.science/hal-01927979}

Submitted on 20 Nov 2018

HAL is a multi-disciplinary open access archive for the deposit and dissemination of scientific research documents, whether they are published or not. The documents may come from teaching and research institutions in France or abroad, or from public or private research centers.
L'archive ouverte pluridisciplinaire HAL, est destinée au dépôt et à la diffusion de documents scientifiques de niveau recherche, publiés ou non, émanant des établissements d'enseignement et de recherche français ou étrangers, des laboratoires publics ou privés. 
The Epstein-Barr virus (EBV) protein EB2 is an mRNA export factor essential for virus production

\author{
Alain Sergeant ${ }^{1,2,3}$, Henri Gruffat ${ }^{1,2,3}$, Evelyne Manet ${ }^{1,2,3}$ \\ ${ }^{I}$ INSERM U758, 46 allee d'Italie, 69364 Lyon Cedex 07, France, ${ }^{2}$ ENSLyon, 46 allee d'Italie, 69364 Lyon Cedex 07, France, \\ ${ }^{3}$ IFR 128 BioSciences Gerland-Lyon Sud, 21 avenue Tony Garnier, 69365, Lyon Cedex 07, France
}

\title{
TABLE OF CONTENTS
}

1.Abstract

2.Introduction

3.The EB2 gene and regulation of its expression

4.EB2 shares properties with $m R N A$ export factors

4.1 EB2 shuttles between the nucleus and the cytoplasm

4.2 EB2 interacts with RNA in vitro and in vivo

4.3 EB2 interacts with cellular RNA export factors

4.4 EB2 induces the cytoplasmic accumulation of $m R N A s$

5. Molecular genetics of EB2

6. HSV1 ICP27, KSHV ORF57 and CMV UL69 do not complement EB2 in virus production

7. The $m R N A$ export function of EB2 is regulated by protein kinase CK2

8. EB2 interacts with the PML body protein Sp110b

10. Acknowledgements

11. References

\section{ABSTRACT}

The EBV early protein EB2 (aka Mta, SM and BMLF1) shares properties with mRNA export factors. It shuttles between the cytoplasm and the nucleus, and interacts with RNA both in vitro and in vivo but with no apparent sequence specificity. EB2 induces the cytoplasmic accumulation of mRNAs generated from intronless and intron-containing genes, likely through interactions with cellular export factors of the TAP/p15 pathway. Using a cell line carrying a viral genome with the EB2 gene deleted, it has been shown that EB2 is essential for the production of infectious virions by facilitating the nuclear export of a subset of early and late viral mRNAs, a function regulated by CK2 phosphorylation of EB2. There are docking sites for both CK2 subunits and for the heterotetrameric enzyme in the EB2 N- and C-terminal domains. Accordingly, EB2 and CK2 co-purify as a complex in which CK2 phosphorylates EB2. CK2 phosphorylation of EB2 at one of the Ser-55, Ser-56 and ser-57 is critical for its mRNA export function and as a consequence, for infectious virus production.

\section{INTRODUCTION}

The Epstein-Barr virus infects more than $95 \%$ of the human adult population. The primary infection is generally silent, but can be the direct cause of a benign disease called infectious mononucleosis (1). After the primary infection, EBV persists lifelong in a latent state, in a sub-population of resting memory $B$ cells (2). The persistence is considered a risk factor for the emergence of EBV-associated malignancies Burkitt's Lymphoma (BL), Nasopharyngeal Carcinoma (NPC), gastric carcinomas, Hodgkin's disease, post-transplant lymphoproliferation disorders (PTLD), T/NK nasal lymphomas, AIDSassociated lymphomas and leiomyosarcomas (reviewed in $(3,4)$ ). EBV has also recently been found in some breast carcinomas biopsies (5-7). Although the hallmark of latency is the absence of a complete viral productive cycle in vitro, EBV productively replicates in vivo in mucosal epithelia and infectious virions are found intermittently in the saliva of healthy carriers (8). This is likely due to the latent infection of blood-borne mononuclear cells that migrate to the oral epithelium where they differentiate into 


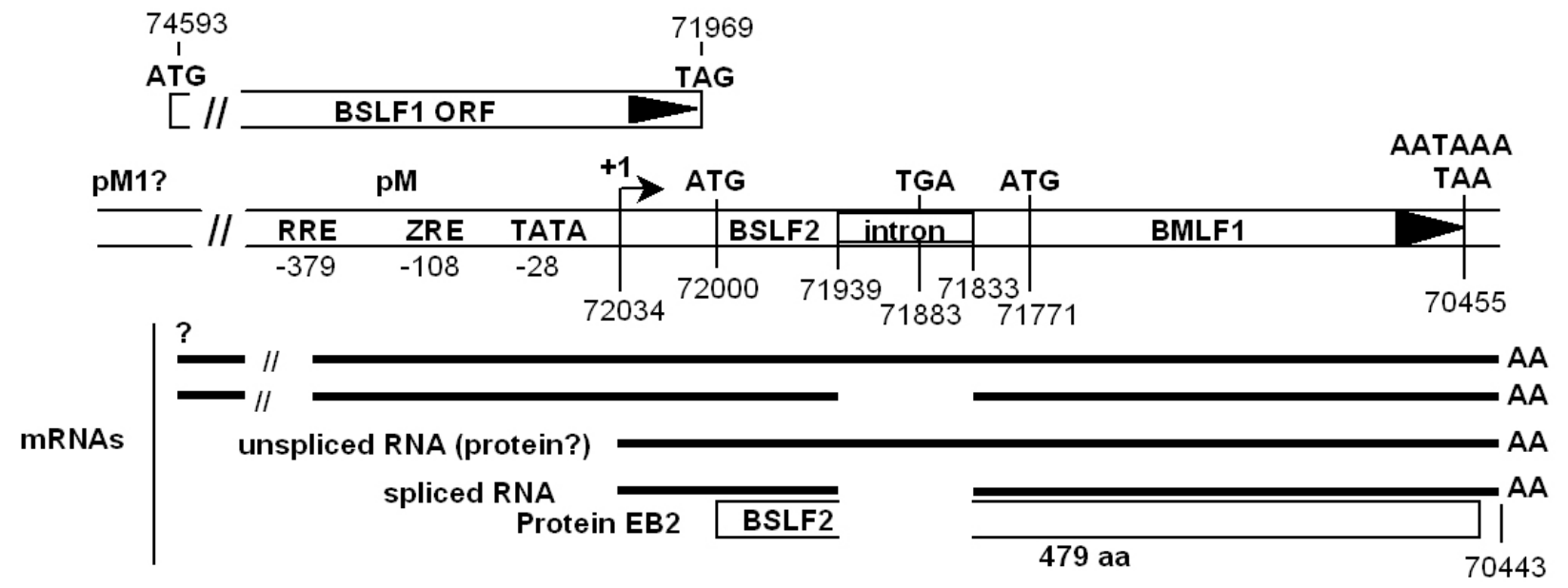

Figure 1. Schematic representation of the EB2 gene, mRNAs and protein product. The relative position (numbers) of the initiation codons, stop codons, borders of the intron, cleavage-polyadenylation site and ORFs are given according to the EBV sequence reconstituted from the B95-8 and Raji genomes (107). At least four mRNAs are transcribed from the EB2 gene locus, and are initiated at two promoters $\mathrm{pM}$ and $\mathrm{pM} 1$, processed by facultative splicing and cleaved and polyadenylated at the same position (70443). In the unspliced mRNAs, the BSLF2 and BMLF1 ORFs are not in phase. The 479 amino acid EB2 protein is expressed from an extension of the BSLF2 ORF generated by excision of the intron from the small precursor RNA initiated at promoter pM. The position of the TATA box, the ZRE (ZEBRA/EB1 Responsive Element) and the RRE (R Responsive Element) in the $\mathrm{pM}$ promoter, are relative to the transcription initiation site +1 .

Langerhans cells and initiate productive EBV replication $(9,10)$. Interestingly, there is strong evidence that reactivation is required for the emergence of EBV associated malignancies (11-13). In vivo, reactivation has also been linked to terminal differentiation of latently infected B cells into plasma cells $(14,15)$ but the signals and the molecular mechanisms that trigger the switch from latency to the productive cycle are not yet known. However, there are models in which some molecular aspects of reactivation have been extensively studied. EBV activates and induces the proliferation of primary $\mathrm{B}$ cells in vitro, a process also called immortalization, leading to the establishment of permanently dividing lymphoblasts. In these cells, there is no productive cycle, and the EBV transcriptome defines a latency of type III which is characterized by the expression of eleven genes, some of which are directly involved in the immortalization process (reviewed in (3)). Cell lines have also been established from EBV-positive BL biopsies, in which there is no productive cycle. The productive cycle can however be induced by treating these proliferating infected cells with various agents like the tumor promoter 12-Otetradecanoyl-phorbol-13-acetate (TPA) (16) associated with sodium butyrate (BA), anti-sIg (17) and Tumor Growth Factor-beta (TGF-beta) (18). In these models, it is now well established that the inducing agents activate the transcription of two viral genes, BZLF1 and BRLF1, whose products are viral transcription factors called respectively EB1 (19) or ZEBRA (20), and R (21). EB1/ZEBRA and $\mathrm{R}$ activate the transcription of all the early genes, some of which are essential for viral DNA replication, a prerequisite for the expression of most late genes, DNA encapsidation and infectious virions production (reviewed in (22)).
Among the early genes, some are not directly involved in viral DNA replication. One of these genes is of particular interest since its product, originally named EB2 (19), but later also called Mta (23) or SM (24) shares properties with mRNA export factors. This review will focus mainly on what is known about the function of EB2 as an mRNA export factor.

\section{THE EB2 GENE AND REGULATION OF ITS EXPRESSION}

The EB2 gene is located on the viral genome in a region containing two open reading frames (ORF) called BSLF2 and BMLF1 (Figure 1). The BMLF1 ORF was reported to be within a region that was the first to be transcribed when latency was disrupted in EBV-infected cells $(25,26)$. It was therefore hypothesized that the expression of BMLF1 was necessary for the initiation of the EBV replicative cycle. Isolation of the cDNAs containing the BMLF1 ORF from Raji cells in which the replicative cycle had been induced by TPA + butyrate (27), demonstrated that four mRNAs generated by facultative splicing and initiated at two promoters, $\mathrm{pM}$ and $\mathrm{pM} 1$, respectively proximal and distal to BSLF2, are transcribed from this region (Figure 1). The two longer cDNAs also contain the BSLF1 ORF which encodes the primase. Sequencing of the cDNAs demonstrated that the corresponding mRNAs were all cleaved and polyadenylated at position 70443 and that in the unspliced mRNAs, the BSLF2 and the BMLF1 ORFs were not in phase. EB2 is expressed from the short spliced mRNA, initiated at promoter $\mathrm{pM}$, and is encoded by an extension of the BSLF2 ORF. Indeed, in the short spliced mRNA, the BSLF2 ORF termination codon is deleted by excision of an intron and the BSLF2 ORF is prolonged until the next 


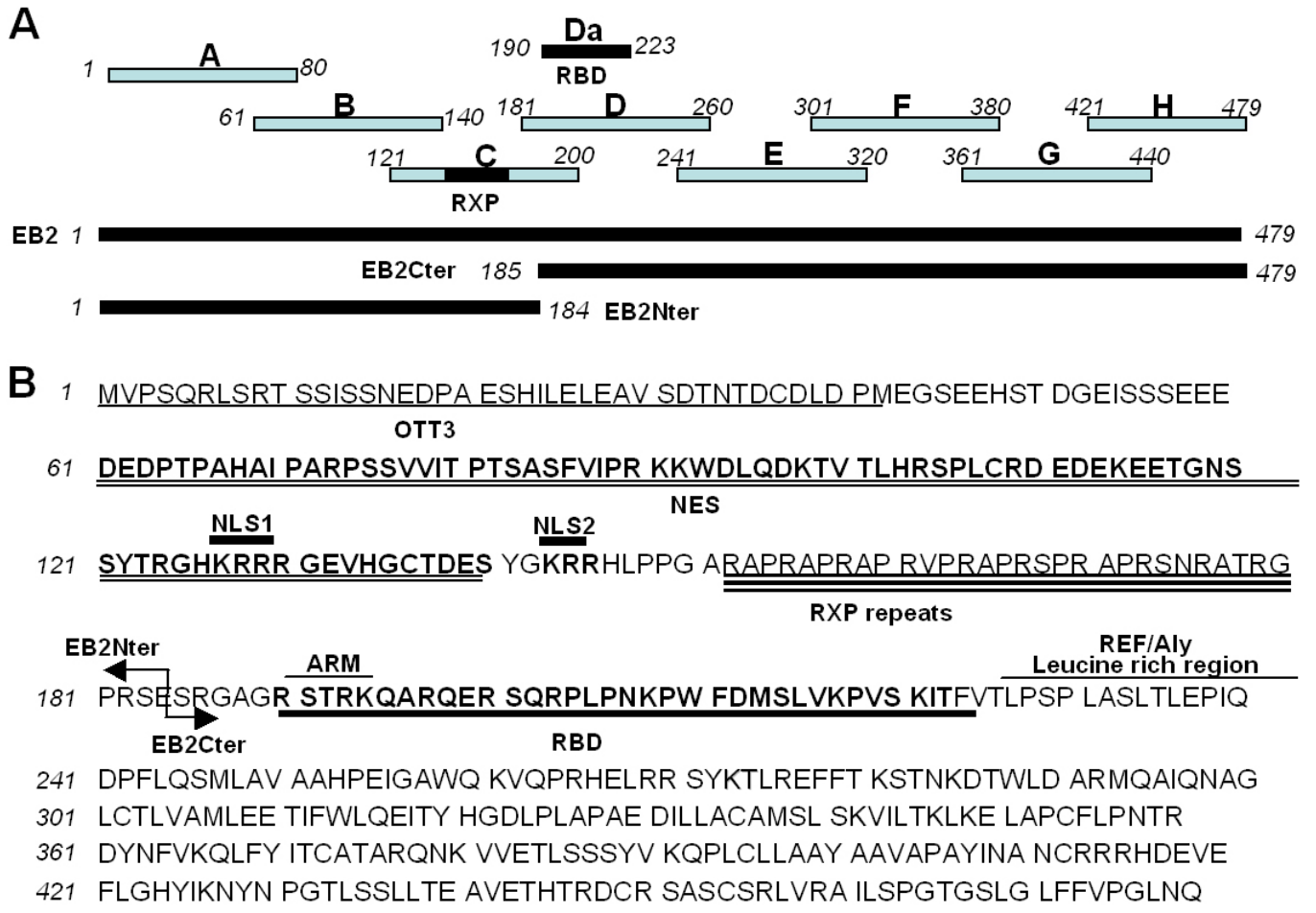

Figure 2. EB2 functional domains and interacting factors. A)- EB2 overlapping polypeptides that were fused to the C-terminus of GST to identify functional domains and interacting proteins. RXP: Arginine-X-Proline repeats; RBD: RNA Binding Domain. B)Functional domains and interacting proteins are located on the EB2 amino acid sequence. The double arrow delineates the Nterminal fragment of EB2 (EBNter) and the C-terminal fragment of EB2 (EB2Cter). NES: Nuclear Export Signal; NLS: Nuclear Localization signal; ARM: Arginine-Rich Motif.

termination codon, at position 70455 (Figure 1). From this spliced mRNA, a 479 amino-acid polypeptide is expressed, generating the EB2 protein. The BMLF1 ORF putative protein product should not be expressed from the two small mRNAs unless there is an internal ribosomal entry site between the BSLF2 and the BMLF1 ORFs and this has not as yet been established. Nevertheless, in one report, coexpression of two proteins, one initiated at the BSLF2 AUG and the other at the BMLF1 AUG have been described in EBV-infected B cells (24). However, the protein initiated at the BSLF2 AUG was much more abundant than the protein initiated at the BMLF1 AUG. No other report has mentioned the expression of the shorter BMLF1 protein. The longer mRNAs, which also contain the BSLF1 ORF, have not been further characterized, and it is not known if EB2 is expressed from these mRNAs. The EB2 gene is an early gene and in the pM promoter a proximal AP-1 site, which is a TPA- and EB1-Responsive Element (ZRE) (27), and a distal R-Responsive Element (RRE) (28) have been characterized (Figure 1). Accordingly, the EB2 gene is transcribed under the control of both EB1/ZEBRA and R. The upstream pM1 promoter has not yet been characterized

\section{EB2 SHARES PROPERTIES WITH MRNA EXPORT FACTORS}

The EB2 protein was first described as a nuclear protein and a transactivator of gene expression as in transiently transfected cells it activated expression of the chloramphenicol acetyl transferase (CAT) intronless gene placed under the control of many different promoters (19, $26,29,30)$. However, it was later shown that the effect of EB2 on gene expression was not promoter dependent but reporter gene dependent and was probably posttranscriptional $(27,31)$. It was finally demonstrated that EB2 has the properties of an RNA export factor and increases the cytoplasmic accumulation of certain intronless viral mRNAs in transient expression assays (32).

\subsection{EB2 shuttles between the nucleus and the cytoplasm} Most RNA export factors shuttle between the nucleus and the cytoplasm and shuttling is essential for their mRNA export function. Shuttling is dependent on two short amino-acid sequences: a Nuclear Localization Signal (NLS) and a Nuclear Export Signal (NES). Transfer of RNA export factors between both compartments is mediated by soluble receptors that bind to the NLS and NES and interact with components of the nuclear pore complex (NPC) (reviewed in (33)). There are two NLSs in EB2, NLS1 and NLS2 (Figure 2B), which act independently and can be transferred to heterologous proteins (34). The cellular receptors that bind these NLS and facilitate the nuclear import of EB2 are not known as yet.

For the prototype RNA export factor Rev from HIV, the nuclear export signal (35) is leucine-rich and 
interacts with CRM1 in a complex including ranGTP, a GTPase in its GTP-bound state (36-39). CRM1 directs Rev to the nuclear pore complex for export (reviewed in (40)). A mutation in the leucine-rich NES of Rev impaired both Rev shuttling and Rev-dependent export of unspliced viral mRNAs (41). EB2 was at first also reported as being CRM1-dependent for its cytoplasmic translocation and to directly interact with CRM1 via a leucine-rich region (Figure 2B) (42). It was further shown that this leucine-rich region contains two putative NESs that when individually fused to a fluorescent nuclear reporter protein induced its cytoplasmic translocation in a CRM1-dependent manner (43). However, other studies using heterokaryon assays, reported that EB2 shuttling was CRM1-independent (44). Indeed, the antibiotic leptomycin B (LMB), a specific CRM1 inhibitor (45), impaired Rev- but not EB2nucleocytoplasmic shuttling. Furthermore, replacement of the leucines by alanines in the EB2 leucine-rich region, a mutation that abolishes the activity of the CRM1-dependent leucine-rich NES (41), had no effect on the nucleocytoplasmic shuttling of EB2 (44). Deletion of the leucinerich region also did not affect EB2's shuttling (34). The final demonstration that the leucine-rich region was not a NES came from microinjection into single nuclei of $\mathrm{HeLa}$ cell polykaryons, of the fusion proteins made between the Glutathione-S-Transferase (GST) and the EB2 overlapping peptides $\mathrm{A}$ to $\mathrm{H}$ (Figure 2A). In these assays, GST-B was transferred to all nuclei of the injected polykaryons, indicating that peptide B contains both an NLS and a NES (Figure 2B), while GST-D which contains the leucine-rich region, remained in the injected nuclei (46). The EB2 Nterminal NES, contained in the B peptide, was transferable and conferred CRM1 independent nucleo-cytoplasmic shuttling to beta-galactosidase. However, although EB2 shuttles between the cytoplasm and the nucleus, it localizes essentially to the nucleus, suggesting that the EB2 import rate is greater than the export rate when substrate mRNAs are limiting. This was also observed for ICP27, the HSV-1 homologue of EB2 in a study using Xenopus laevis oocytes (47). It is noteworthy that deletion of the B region in EB2 (targeted to the nucleus by a heterologous NLS in order to compensate for the concomitant deletion of one of the two EB2 NLS) did not impair nucleo-cytoplasmic shuttling, suggesting that there is a second NES in EB2 (our unpublished results). The second NES is evidently not the leucine-rich region since the $\mathrm{C}$-terminal part of EB2 (Figure 2B, EB2Cter), targeted to the nucleus by a heterologous NLS, does not shuttle, even though it contains the leucine-rich region (34). On the contrary, the $\mathrm{N}$ terminal part of EB2 (Figure 2B, EB2Nter) which contains the CRM-1-independent NES does shuttle (our unpublished results). Thus, there are probably more than one NES in $\mathrm{EB} 2$, all localized in the N-terminal part of the protein. It is not yet known which cellular factor(s) binds to these Nterminal NESs of EB2 to facilitate its nuclear export.

\subsection{EB2 interacts with RNA in vitro and in vivo}

RNA export factors can bind RNA via a domain that directly recognizes either a specific RNA sequence (the case for some members of the family of splicing factors containing serine-arginine repeats (SR proteins)) (48) or a specific RNA structure (as in the case for TAP/NXF1 (49),
HIV Rev (50) and RBM15/OTT1 (51)). RNA export factors can also be recruited to RNA via interaction with components of complexes loaded onto RNA during splicing $(52,53)$, transcription elongation (54) or 5', capping (55).

By using the GST fusion peptides depicted in Figure 2A, in RNA mobility shift assays, it has been shown that EB2 contains an RNA-binding domain (RBD) located in peptide D (34). The EB2 RBD contains the motif TRKQAR, rich in basic residues (Figure 2B, ARM: Arginine Rich Motif), which is reminiscent of the argininerich motif TRRRER originally found in the bacteriophage lambda $\mathrm{N}$ protein (56) and then in many other RNAbinding proteins including HIV-1 Rev (TRQARR) and Tat (TRGKGR) $(57,58)$. The shorter RBD-containing peptide Da (Figure 2A and Figure 2B), fused to GST, bound in vitro with no apparent specificity to 180 and 72 nucleotide RNAs corresponding respectively to the second exon and the first intron of the human beta-globin gene (34). GST-Da bound several times to both RNA molecules, and the number of GST-Da:RNA complexes increased with increase in GST-Da concentration. Although the RNAs used in the in vitro binding assays were potentially highly structured as evaluated by MFOLD (59), GST-Da bound to both RNAs every $20 \mathrm{nt}$ or so. Purified full length EB2 also bound in vitro several times to both RNAs (our unpublished data). It would thus appear that the RNAbinding domain of EB2 can directly interact with RNA in vitro and occupies sites covering the entire RNA molecule, suggesting that the EB2 RBD could unfold the RNA in vitro.

Another RNA-binding domain has been described for EB2 which contains several Arginine-XProline repeats (Figure 2B, RXP repeats), similar to that present in the HSV-1 US11 protein (60). The RXP repeats bound RNA in vitro when exposed at the C-terminus of the GST-RXP fusion protein (61), or after proteolytic cleavage of the GST-EB2 fusion protein and exposure at the Cterminus of the truncated protein (62). A shorter protein initiated at the BMLF1 AUG and fused at the C-terminus of GST also bound RNA in vitro but again the fusion protein was degraded and the RXP domain was probably exposed at the C-terminus of the GST-BMLF1 fusion protein (32). However, the RXP repeats did not bind RNA when embedded within the GST-C fusion protein and EB2Cter which lacks the RXP repeats (Figure 2A), bound RNA in a Northwestern assay (34). Furthermore, EB2 could be coimmunoprecipitated with target RNAs from transfected cells when the RXP repeats were deleted (62) but not when the RBD was deleted (34), strongly indicating that EB2 directly interacts with RNA in living cells via the RBD. Again no specific RNA sequence or structure was identified for directing EB2 to target RNAs in vivo.

\subsection{EB2 interacts with cellular RNA export factors}

The assembly of the export-competent mRNPs in mammalian cells, starts with capping at the 5'-end of the nascent RNA and subsequent binding of the cap-binding complex composed of CBP80 and CBP20. This step is followed by splicing-dependent deposition of the exon- 


\section{A InTRON-CONTAINING GENES}

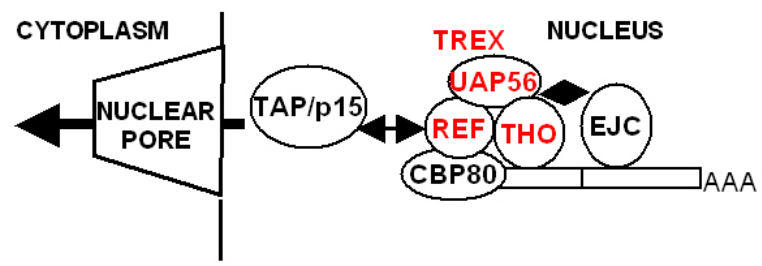

B INTRONLESS GENES

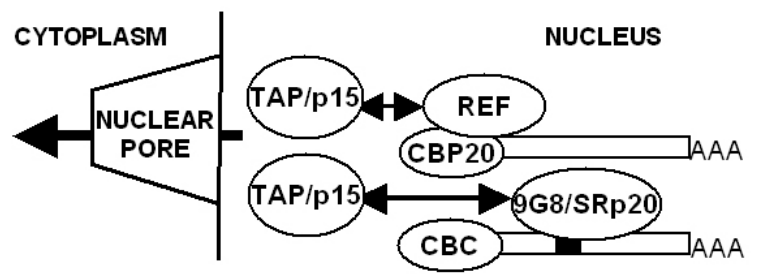

Figure 3. Models for cellular mRNA export. A)- Nuclear export of mRNAs that undergo splicing. 5' recruitment by CBP80 of REF/Aly bound to UAP56 in the TREX complex is splicing dependent, probably via interaction with the Exon Junction Complex (EJC), which is deposited on the RNA during splicing. TAP/p15 facilitates the translocation through the nuclear pore of the export-competent mRNP by contacting REF/Aly. B)- The nuclear export of mRNAs generated from intronless genes is either due to recruitment of REF/Aly by CBP20, or by binding of SR proteins to the mRNA. In both cases, TAP/p15 facilitates nuclear export. $\mathrm{CBC}$, Cap-Binding Complex.

junction complex (EJC) for intron-containing genes, by cleavage and polyadenylation at the 3 'end, and by the binding of RNA-export adaptor proteins (reviewed in (63)). Each of these steps is carried out co-transcriptionally by distinct multi-protein complexes, which are physically and functionally coupled $(64,65)$. In a more recent model (Figure 3A), fully processed mRNPs generated from introncontaining genes are exported via 5'-end recruitment (by CBP80) of the RNA export factor REF/Aly bound to UAP56 in the transcription elongation complex TREX which is stably associated with RNA probably by interacting with the EJC complex (55). REF/Aly would then interact with $\mathrm{TAP} / \mathrm{p} 15$ that facilitates the export of mRNPs by interacting with nucleoporins via its C-terminal NES. For mRNPs generated from intronless genes, one pathway of export involves binding of SR proteins 9G8 and SRp20 to specific RNA sequences, which facilitate export by directly recruiting TAP/p $15(48,66)$ (Figure $3 \mathrm{~B})$. In another alternative pathway REF/Aly would be recruited to intronless mRNAs by CBP20, which facilitates export by recruiting TAP/p15 (67) (Figure 3B). From the above models, it can be concluded that in mammalian cells, UAP56 and REF/Aly are essential mRNA export adaptors, while TAP/p15 is a promiscuous mRNA export receptor.

EB2, REF/Aly and TAP co-immunoprecipitate from living cells but this complex is disrupted by ribonuclease treatment, suggesting that it is stabilized by RNA (34). Interestingly, the REF/Aly interaction domain in EB2 was located in the leucine-rich region (Figure 2B) and
EB2-mediated mRNA export was severely impaired by deletion of this region. In in vitro binding assays, EB2 interacted with the C-terminal region of $\mathrm{REF} / \mathrm{Aly}$. The interaction was not disrupted by ribonuclease treatment, demonstrating a direct interaction between EB2 and $\mathrm{REF} / \mathrm{Aly}$ in vitro (34). Thus EB2 appears to recruit TAP indirectly via REF/Aly to export mRNAs.

In a yeast two-hybrid screen, human OTT3 was identified as an EB2-interacting factor (68). OTT3/RBM15B is a member of the Spen family of proteins which include human OTT1/RBM15 and SHARP (69). These factors are characterized by several RNA Recognition Motifs (RRMs) located at their N-termini and by a C-terminal conserved SPOC (Spen Paralog Ortholog C-terminal) domain. Recently, RBM15 has been described as an mRNA export factor (51) that binds specifically via its RRMs to the transport element RTE identified in mouse retrotransposon unspliced mRNAs and directly interacts with TAP/p15 via the SPOC domain, which facilitates the nuclear export of RTE-containing mRNAs. EB2 interacts with the SPOC domains of RBM15, OTT3 and SHARP but it is not known at present if OTT3 and SHARP are also RNA export factors. EB2 and TAP/p15 both interact with the SPOC domain of OTT1 but it is not yet known whether this is with the same or different regions in the SPOC domain. OTT3 interacts with EB2 via amino acids 10 to 40 at the N-terminal (Figure 2B), while RBM15 and SHARP interact with the C-terminus of EB2 (68). In conclusion, EB2 appears to export mRNAs to which it is bound, by directly contacting several RNA export adaptor proteins of the TAP/p15 pathway.

\subsection{EB2 induces the cytoplasmic accumulation of mRNAs}

In line with the observations that EB2 shares properties with mRNA export factors, EB2 has been shown to affect the cytoplasmic accumulation of both intronless and unspliced mRNAs. However, there is little agreement between the results obtained by different laboratories. One report suggested that EB2 was inducing the cytoplasmic accumulation of mRNAs generated from transfected intronless artificial reporter genes while inhibiting the export of mRNAs generated from transfected introncontaining artificial reporter genes (70). However, the same laboratory also showed that EB2 exported STAT1alphaand STAT1beta-spliced mRNAs in EBV-negative B cells (71). Other assays made use of a reporter gene called pDM128 (Figure 4A) (72), widely used to assess if a given protein has RNA export activity. This construction is an artificial gene with two exons and the HIV-1 tat/rev intron containing the CAT gene. The intron has suboptimal signals in the 3' splice site (73). Upon transient expression of pDM128 pre-mRNA in cells, the intron is excised prior to nuclear export of the RNA and little or no CAT protein is found in the cell extract. However, if RNA export factors are tethered to the intron via a specific RNA-binding element, then unspliced RNAs are exported and CAT protein can be detected in the cell extract (74). In this assay, EB2 greatly enhanced the export of pDM128 unspliced RNAs even in the absence of a specific RNAbinding motif (Figure 4A) (44). In another assay, the wild 

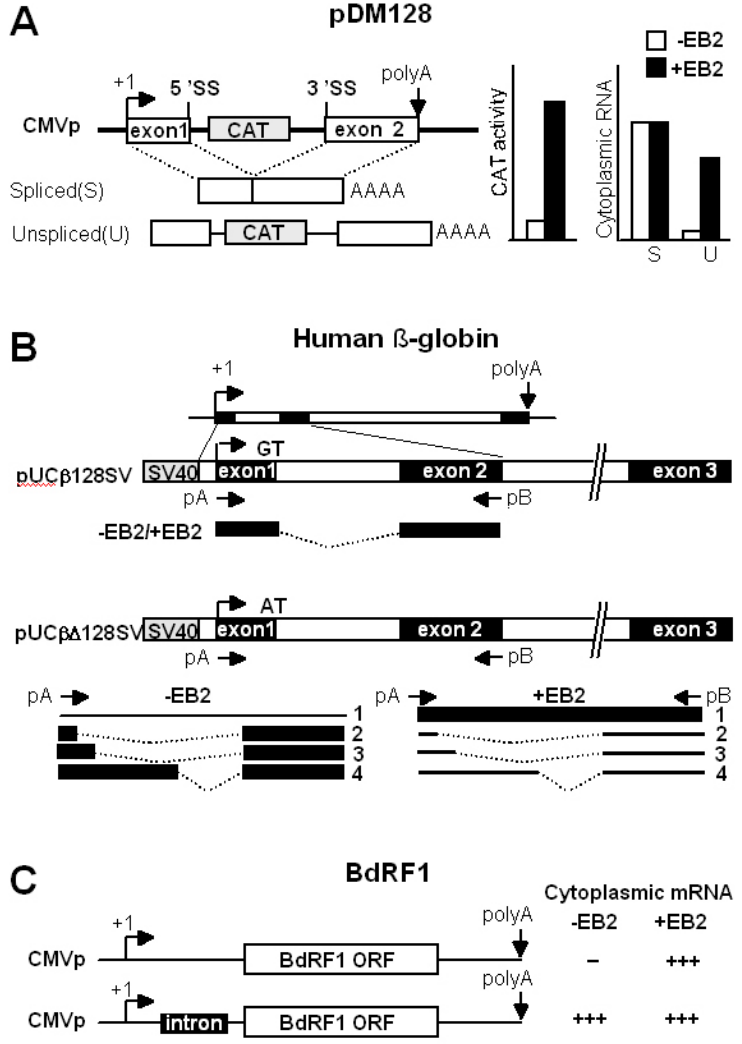

Figure 4. EB2 exports unspliced and intronless mRNAs. A)-Schematic representation of pDM128, of the CAT activity and of the spliced (S) or unspliced (U) cytoplasmic mRNAs expressed in the absence or presence of EB2. B)Schematic representation of pUCbeta128SV and pUCbeta $\Delta 128 \mathrm{SV}$ carrying the wt human beta globin gene or its beta thalassemia variant respectively, under the control of the SV40 early promoter. Only splicing of the first intron has been assessed by RT-PCR using primers $\mathrm{pA}$ and $\mathrm{pB}$. Similar amounts of spliced wt beta globin mRNA is exported in the presence or absence of EB2 (-EB2/+EB2 under the reporter plasmid pUCbeta128SV). Four RNAs are expressed from the beta-thalassemia reporter plasmid, 1: unspliced RNA; 2,3 and 4: spliced RNAs generated by the use of three facultative cryptic 5' splice sites. In the presence of EB2, the unspliced RNA is the major RNA species exported (the thickness of the schematic mRNAs is directly proportional to the efficiency of their export). C)The viral BdRF1 intronless reporter gene generates an mRNA that is only exported in the presence of EB2. No effect by EB2 on the export of the BdRF1 mRNA that has undergone splicing is detected.

type human beta-globin gene and its thalassemic allele were used (Figure 4B) $(75,76)$. The beta-thalassemic gene contains a G-to-A transition at position one of the first intron which causes the activation of three cryptic 5' splice sites. In this assay, EB2 had no effect on the nuclear export of wt spliced beta-globin mRNA, but strongly increased the export of unspliced beta-thalassemic RNA which was associated with a decreased export of spliced beta- thalassemic mRNAs (Figure 4B) $(44,61)$. Most of the early and late EBV mRNAs are generated from intron-less genes, and in transient expression assays EB2 increases the export of some of these mRNAs $(32,77)$. However, when an intron was added to some of these otherwise intronless genes, then EB2 had no effect on the already efficient export of the mRNAs that had undergone splicing (Figure 4C) $(32,77)$. In conclusion, in transient expression assays, EB2 increases the cytoplasmic accumulation (export) of mRNAs generated from intronless genes as well as of unspliced mRNAs generated from introns containing genes but only if they contain facultative or cryptic splice sites.

It should be stressed that an EB2 region essential for its effect on the export of intron-containing and intronless mRNAs has been located in the 35 amino acids at the C-terminal (78). However, mutagenesis in this region mostly generated EB2 proteins that were abnormally distributed in the nucleus as dense separate foci, representing insoluble aggregates in which EB2 was inactive. Moreover, as compared to the diffuse nucleoplasmic localization of wt EB2, several overlapping deletions covering the 250 amino acids at the EB2 Cterminal generated the same phenotype - dense separate nuclear foci (Figure 5, our unpublished results) - and these EB2 mutants were inactive in an RNA-export assay (61). This suggests that the C-terminal part of EB2 is highly structured and that disruption of the structure induces aggregation and inactivation of the protein. It should also be noted that as EB2 has been reported to self-associate in vitro, via a region located in the 200 amino acids at the $\mathrm{C}$ terminal (79), it is also possible that inactivation of selfassociation induces aggregation and inactivation of EB2 in vivo.

\section{MOLECULAR GENETICS OF EB2}

In order to study the function of EB2 in the context of the EBV productive cycle, an EBV mutant was generated in which the EB2 gene was deleted. The mutated viral genome was then introduced into 293 cells and one cell clone called $293_{\text {BMLF1-KO was selected. (80). In order to }}$ induce the productive cycle of EBV in cells latently infected with the virus, it is necessary and sufficient to transiently express the EBV transcription factor EB1/ZEBRA which is the activator of both EBV early gene expression, including that of EB2, and viral DNA replication. The amount of virions produced by the $293_{\text {BMLF1-KO }}$ cells can be evaluated by infecting B cells with the 293 BMLF1Ko supernatant. Due to the constitutive expression of the GFP protein from the EBV recombinant genome, infected cells are bright green under UV light and can be quantified by FACS analysis. In this assay, 293 BMLF1-Ko cells harbouring the EB2-defective EBV genome only produced infectious EBV particles when both EB1 and EB2 were transiently expressed, demonstrating that EB2 is essential for the production of infectious virions (80).

In this transcomplementation assay, it was shown that most of the late viral mRNAs but only a subset of the early viral mRNAs are exported by EB2 (Figure 6). This was achieved by semi-quantitative RT-PCR analysis (77, 

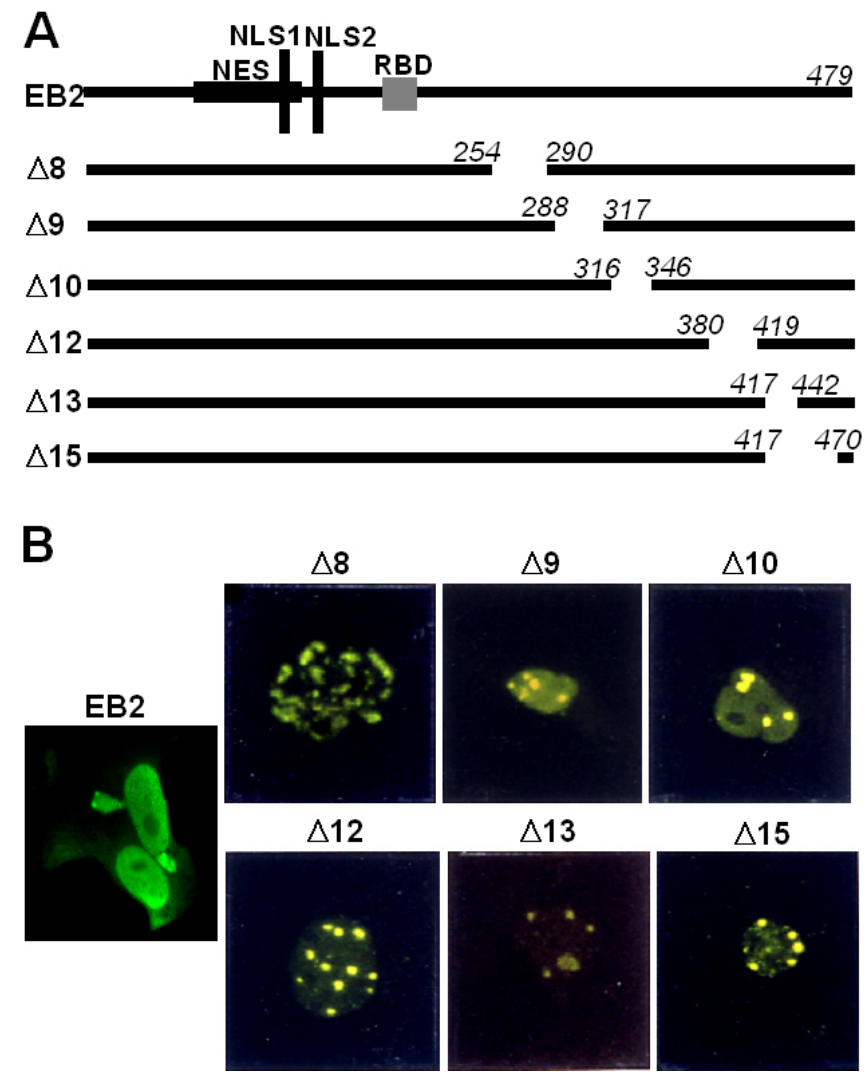

Figure 5. Deletions in the C-terminal half of EB2 induce its nuclear aggregation. A)- Schematic representation of EB2 Cterminal amino acid deletions. B)- Nuclear distribution in dense separate nuclear foci of EB2 mutated proteins expressed in Cos-1 cells, as visualized by indirect immunofluorescence.

$80)$ and by oligonucleotide arrays (81). These results have important implications. Firstly, the inefficient export of the early mRNAs encoding the primase and the DNA polymerase in 293 BMLF1-KO cells expressing EB1 alone, was associated with poor (77) or absent (81) viral DNA replication. As viral DNA replication is a prerequisite for the expression of the late viral genes, the defect in late mRNA expression in the absence of EB2 could be the consequence of poor replication of the viral DNA. However, although transfection of primase and DNA polymerase expression vectors in $293_{\mathrm{BMLF1} 1 \mathrm{KO}}$ cells together with EB1 partially rescued DNA replication, the transfected cells produced no infectious virions (81). This could be due to the fact that the expression of the single stranded DNAbinding protein is also EB2-dependent (80). Thus expression vectors for the single stranded DNA-binding protein should have been co-transfected together with expression vectors for EB1, the primase, and the DNA polymerase, to efficiently rescue DNA replication. Nevertheless, about 12 late genes were detectably expressed in $293_{\text {BMLF1-KO }}$ cells in which DNA replication was partially rescued, indicating that replication per se increases the expression of some late genes and that the corresponding mRNAs were exported in the absence of EB2. It is noteworthy that their export was further increased by EB2. However, in conditions that partially rescued replication, the majority of the late mRNAs were strictly dependent on EB2 to be exported. These results suggest that EB2 is required for the efficient export of the majority of the viral late mRNAs, and for the production of infectious virions. Secondly, expression in $293_{\text {BMLF1-KO }}$ cells of both EB1 and an EB2 mutant with the REF/Aly interacting domain deleted, induced viral DNA replication efficiently but very inefficiently rescued the production of infectious virions (80). This strongly suggests that EB2 mainly exports late viral mRNAs via the REF/TAP pathway and that the early mRNAs encoding proteins essential for the replication of viral DNA are exported by EB2 via another pathway. Thirdly, the absolute requirement of $\mathrm{EB} 2$ for the efficient production of infectious virions has also been linked to a defect in the intranuclear assembly of capsids but this was expected since EB2 is required for the efficient export of the mRNAs encoding the capsid proteins (77).

It is clear from the transcomplementation assay, that some early and most late EBV mRNAs are exported by EB2. Although most of these mRNAs are generated from intronless genes, EB2 also exports unspliced viral mRNAs. Indeed, the EBV BLLF1 late gene contains an intron and both spliced and unspliced BLLF1 mRNAs must be exported to generate respectively gp220 and gp340, two glycoproteins essential for the infection of cells by EBV (82). When 293 BMLF1-Ko cells, were transfected with EB1 

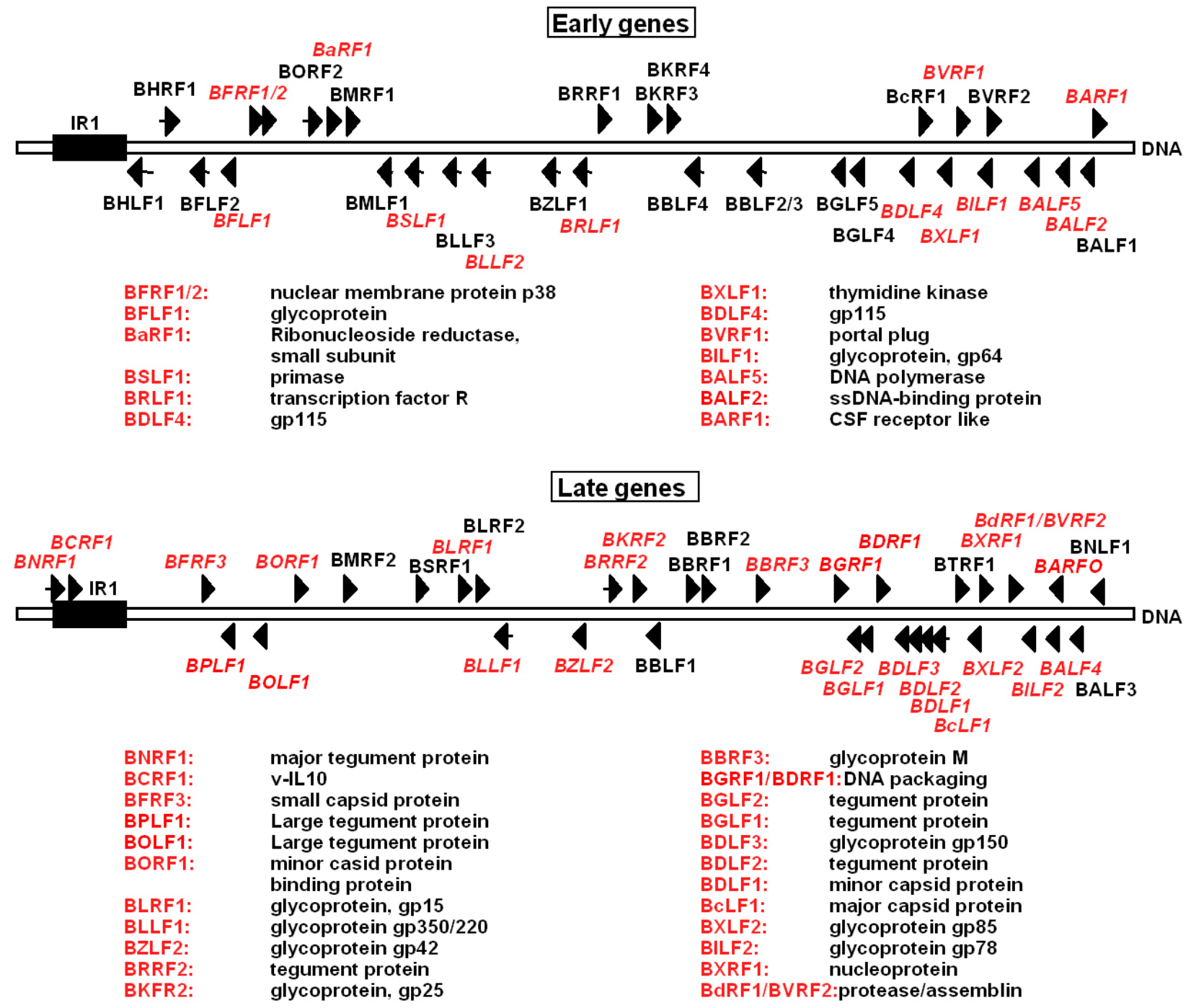

Figure 6. EB2 exports a subset of early and late viral mRNAs. The mRNAs exported by EB2 characterized by RT-PCR and oligonucleotide arrays, are indicated in red italics over and under the schematic representation of the viral genome (DNA). Their location and the orientation of their synthesis are indicated by black arrowheads. The protein encoded by each mRNAs exported by EB2 is also indicated. IR1: Internal Repeats 1.

alone, only the spliced mRNA was expressed and exported, whereas when both EB1 and EB2 were expressed the export of the unspliced mRNA was induced and the export of the spliced RNA remained as efficient as when EB1 was expressed alone (77). Therefore, EB2 also exports unspliced viral mRNAs carrying facultative splice sites, which is in agreement with what was observed in transient expression assays using heterologous genes (see 4.4).

Using the transcomplementation assay, it was also shown that the EB2 mutant lacking the RNAbinding domain did not rescue the production of infectious virions by $293_{\text {BMLF1-KO }}$ cells, suggesting that EB2-binding to RNA in vivo is required for the production of EBV-infectious virions (34). On the contrary, EB2 with the OTT3 N-terminal binding domain deleted efficiently rescued the production of infectious viral particles (our unpublished results). However, since this EB2 mutant still potentially interacts with RBM15/OTT1, this result is not so surprising as these proteins could transcomplement each others function. Finally, none of the EB2 mutants generated in the $\mathrm{C}$-terminal 35 amino acids that localized abnormally in the nucleus, rescued the production of infectious virions by $293_{\text {BMLF1-KO }}$ cells (78). In conclusion: 1) DNA replication and EB2 are both required for an efficient nuclear export of the majority of late viral genes, probably mostly mediated by the REF/TAP pathway; 2) EB2-mediated export of early genes probably depends on a pathway that does not involve REF; 3) many early and some late intronless viral mRNAs are efficiently exported in the absence of EB2 via pathways that have not as yet been identified. 


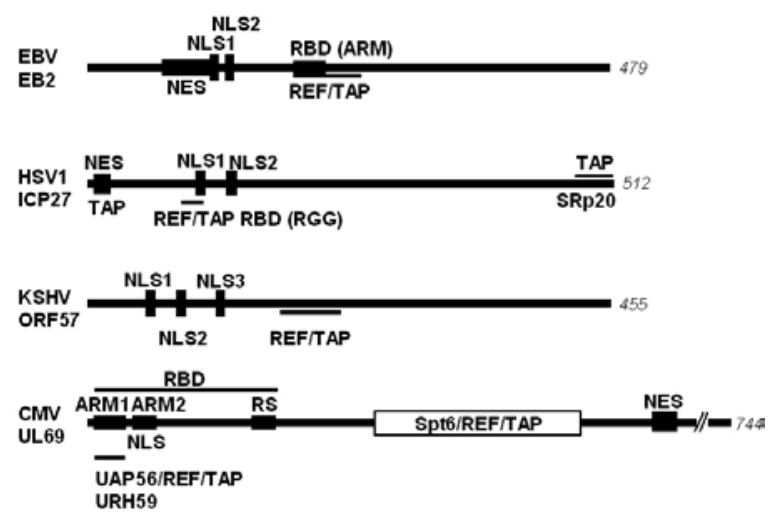

Figure 7. Functional domains and factors that interact with EB2 and with its functional homologues. Schematic representation of the functional domains of EB2, HSV-1 ICP27, KSHV ORF57 and CMV UL69 and of the regions that interact with cellular factors. RBD: RNA Binding Domain; ARM: Arginine Rich Motif; RGG: Arginine Glycine rich motif; RS: Arginine Serine rich motif.

\section{HSV1 ICP27, KSHV ORF57 AND CMV UL69 DO NOT COMPLEMENT EB2 IN VIRUS PRODUCTION}

Several human herpes viruses carry a gene in their genome whose product is functionally similar to EB2, for example, the Herpes Simplex virus type 1 (HSV1) protein ICP27 (47, 83, 84), the Cytomegalovirus (CMV) protein UL69 (85), and the Kaposi's Sarcoma-associated Herpes Virus (KSHV) protein ORF 57 (86) (Figure 7). At least for HSV1 and KSHV, the respective deletion of the ICP27 (87) and ORF57 (88) genes, abolished both the production of infectious viral particles and the cytoplasmic accumulation of specific viral mRNAs, demonstrating that, like EB2, ICP27 and ORF57 are essential viral factors.

Importantly, like EB2, HSV1 ICP27 (47, 84), CMV UL69 (89) and KSHV ORF57 (86) shuttle between the nucleus and the cytoplasm in a CRM1-independent manner. Like EB2, they also induce the cytoplasmic accumulation of some but not all viral mRNAs $(85,90,91)$, by interacting with cellular adaptors of the $\mathrm{TAP} / \mathrm{p} 15$ receptor pathway (Figure 7). The CMV UL69 protein interacts with the DEXD/H-box RNA helicase UAP56 (85), a cellular factor that in metazoans appears to interact with REF/Aly which in turn makes contact with TAP/p15. UL69 also interacts with the human homologue of yeast Spt6 (92), a histone $\mathrm{H} 3-\mathrm{H} 4$ chaperone that maintains native chromatin structure behind elongating RNA Pol II (93) and mediates nucleosome reassembly at promoters during transcriptional repression in yeast (94). Human Spt6 binds RNA Pol II as well as Iws1, which associate with REF/Aly (95). Thus interaction of UL69 with both Spt6 and UAP56 likely mediates the efficient recruitment of $\mathrm{TAP} / \mathrm{p} 15$ for the export of intronless viral mRNAs. ICP27 interacts with REF and TAP/p15 $(47,84)$ and with the splicing factor SRp20 that binds directly to TAP, although a function of SRp20 in ICP27-mediated mRNA export has not been documented (96). The KSHV ORF57 also interacts with
REF and TAP/p15 (86). In addition, UL69 (97), ICP27 (83), EB2 (34) and ORF57 (86) bind to RNA in vitro and in vivo, but the binding is not sequence or structure specific. Surprisingly, RNA-binding of UL69 is not a prerequisite for the nuclear export of unspliced pDM128 mRNAs (97). Nevertheless, since EB2, ICP27, UL69 and ORF57 bind non-specifically to viral RNAs in vivo and recruit adaptor proteins to export RNAs via the REF/TAP pathway, it could have been expected that they would trancomplement each other in the export of viral mRNAs and in the production of infectious virions. Yet, when inserted into a HSV1 ICP27-null mutant, EB2 did not efficiently complement ICP27 in inducing the production of infectious virions (98). When provided in trans, neither ICP27, UL69 (80) nor KSHV ORF57 (88) complemented EB2, in inducing the production of infectious virions from $293_{\text {BMLF1-KO }}$ cells. These results suggest that some of the known RNA-binding proteins that coat cellular mRNPs during their biogenesis bind preferentially to specific subpopulations of viral mRNPs and specifically recruit one or the other of the herpes virus export factors. The observation that EB2, ICP27, UL69 and ORF57 are absolutely required for the export of viral mRNAs and the production of infectious virions, strongly suggests that viral mRNAs inefficiently bind REF or other RNA export adaptors in the absence of viral export factors.

\section{THE MRNA EXPORT FUNCTION OF EB2 IS REGULATED BY PROTEIN KINASE CK2}

EB2 is a nuclear phosphoprotein (99) which is phosphorylated by protein kinase CK2 (24) but whether CK2 binds to EB2 or whether EB2 phosphorylation by CK2 affects its mRNA export function had not been established. Protein Kinase CK2 is a heterotetrameric complex consisting of a stable association of two catalytic subunits (alpha or alpha') and two regulatory beta subunits (Figure 8), that phosphorylates many various substrates localized in different cellular compartments (for a review see, (100)). However, free populations of CK2 subunits can also exist within the same cell (101). Both CK2 subunits are independently targeted to the nucleus where they exhibit differential mobility and CK2alpha but not CK2beta, shuttles between the nucleus and the cytoplasm. Thus, CK2 can act not only as a hetero-tetrameric holoenzyme but also as free populations of both subunits, either alone or in association with different partners, and in different subcellular compartments.

Our recent in vitro studies (102) show that both the CK2 alpha catalytic subunit and the beta regulatory subunit bind individually but more efficiently as the alpha2beta2 heterotetrameric holoenzyme, to the region containing the N-terminal NES of EB2 (Figure 8). It is evident that docking of CK2 or of CK2 subunits in the region containing the NES does not interfere with the nucleo-cytoplasmic shuttling of EB2. It is also unlikely that CK2 alpha participates in the nucleo-cytoplasmic shuttling of EB2 since EB2 shuttling is resistant to the CRM1 inhibitor leptomycin B (34) whereas this inhibits CK2 alpha shuttling (101). The alpha subunit and more efficiently the beta subunit also bind individually in vitro at 


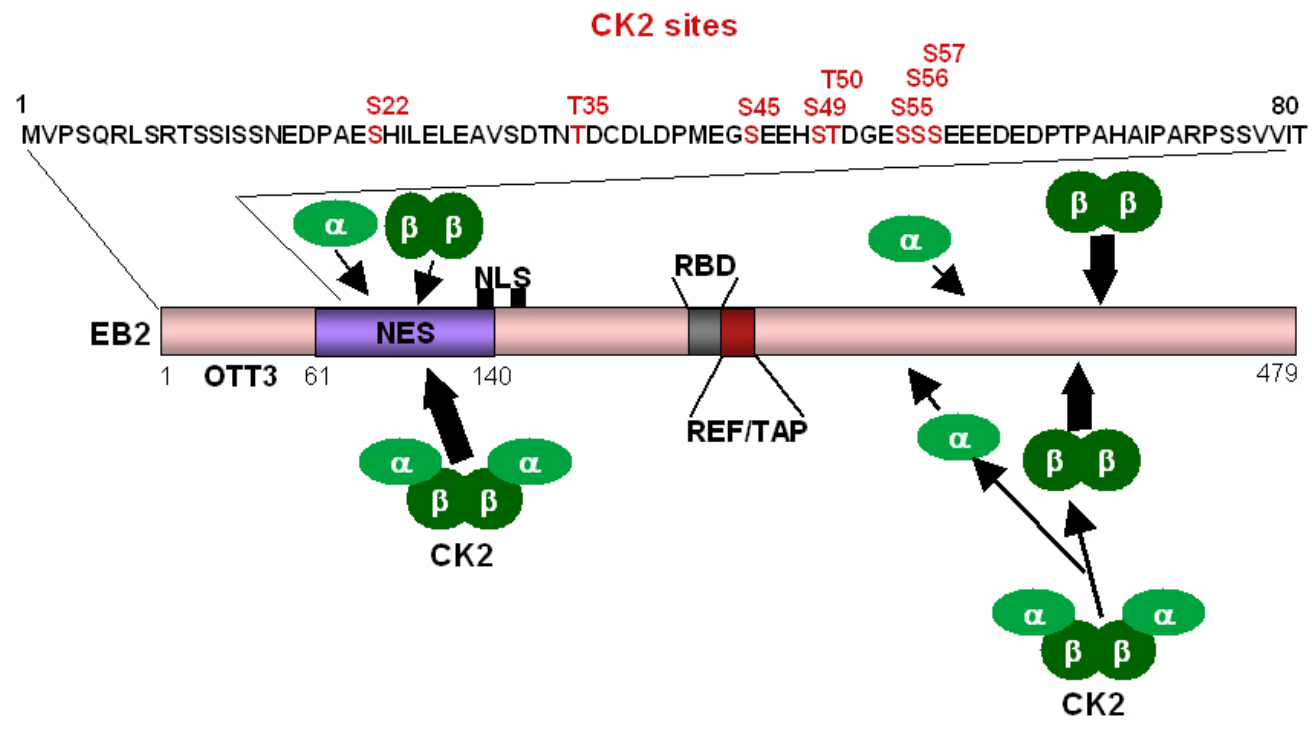

Figure 8. EB2 interacts with and is phosphorylated by proteine kinase CK2. Individual CK2 subunits interact with both the Nand C-terminus of EB2 in vitro. The heterotetrameric CK2 also binds to the N-terminus of EB2, whereas incubation of the heterotetrameric CK2 with the C-terminus of EB2 leads to efficient binding of the beta-subunit and weak binding of the alpha subunit (the thickness of the arrows is directly proportional to the efficiency of binding). The N-terminal CK2 phosphorylation sites are shown, including serines 55, 56 and 57. The EB2 regions interacting with OTT3, REF and TAP are also shown.

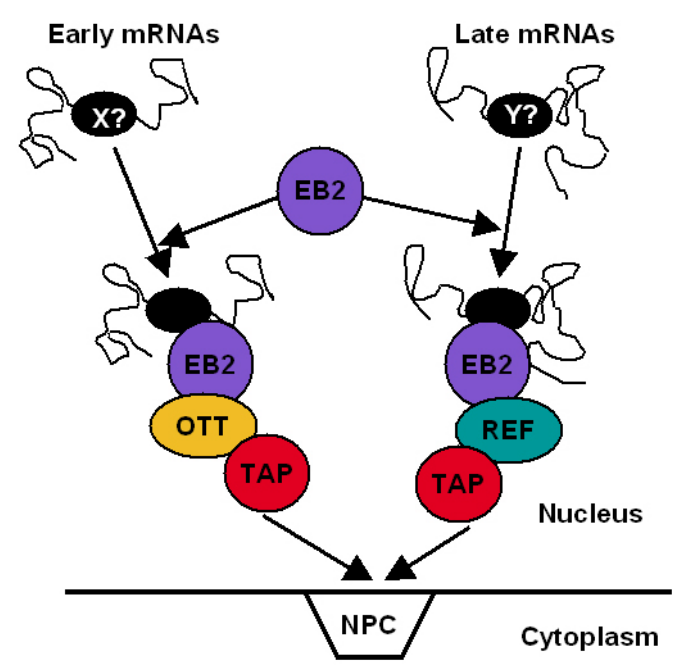

Figure 9. Models for EB2-mediated mRNA export. The viral mRNAs do not bind REF efficiently or other export adaptors in the absence of EB2. EB2 is recruited to early and late intronless mRNAs by different factors that by as yet unknown mechanisms, direct the binding of EB2 to RNAs, the recruitment by EB2 of different export adaptors and the export of the mRNAs.

the C-terminus of EB2 (Figure 8). Interestingly, when the holoenzyme is incubated in vitro with the EB2 C-terminal 295 amino acids, the beta subunit binds much more efficiently than the alpha subunit. This suggests that interaction of CK2 with the C-terminus of EB2 destabilizes the heterotetrameric enzyme, leading to efficient binding of the beta subunit alone, and weak binding of the alpha subunit, alone and/or as a heterotetrameric complex.

Only the N-terminus of EB2 is phosphorylated by CK2 in vitro. All the phosphorylation sites are located between amino acids 1 and 60, upstream of the CK2 binding site, and include the three serines S55, S56 and S57 located next to the NES (Figure 8). EB2 and CK2 co-purify as a complex from living cells, and in this complex, CK2 phosphorylates EB2 at all N-terminal sites. However, among several phosphorylation mutants generated, only the substitution of the three serines 55,56 and 57 by alanines (mutant EB2S3A) had a functional effect unlike their replacement by glutamates (mutant EB2S3E). Indeed, the EB2 phosphorylation ablation mutant EB2S3A inefficiently rescued the production of infectious virions by $293_{\text {BMLF1KO }}$ 
cells, whereas the EB2 phosphomimetic mutant EB2S3E was as efficient as wild type EB2. Although the three serines 55, 56 and 57 are located next to the NES, their mutation to alanine or glutamate residues did not affect the nucleo-cytoplasmic shuttling of EB2. Rather, and in line with the mRNA export function of EB2, the incapacity of $\mathrm{EB} 2 \mathrm{~S} 3 \mathrm{~A}$ to rescue infectious virus production was associated with the inefficient cytoplasmic accumulation of several late mRNAs, including those encoding the EBV capsid proteins. This strongly suggests that the mRNA export function of EB2, and as a consequence the production of infectious virus, is regulated by protein kinase CK2. However, why CK2 phosphorylation of EB2 at the level of at least one of the Ser-55, -56 and -57 residues, is critical for the efficient export of several viral late mRNAs is not known at present. It is noteworthy that phosphorylation per se is not required, since EB2S3E is functionally equivalent to EB2wt. It is also not known what function is associated with the binding of the alpha and beta subunits to the EB2 C-terminus.

\section{EB2 INTERACTS WITH THE PML BODY PROTEIN Sp110b}

The nucleus of mammalian cells contains several nuclear domains or foci, which contain multiple proteins. These nuclear bodies include nucleoli, PML bodies (also called ND10), splicing speckles, Cajal bodies and paraspeckles. The proteins found in these subnuclear structures interact dynamically with one or the other of these bodies, and are involved in different nuclear functions, such as ribosome biogenesis, transcription and RNA splicing. EB2 has been found to interact with Sp110b, a splice variant of the PML body Sp110 component (103). PML bodies contain about 80 proteins involved in transcription, DNA repair, splicing, histone modification, and chromatin remodeling. These proteins interact dynamically with the PML bodies and can also be found in the nucleolus, in splicing speckles and at telomeres. More importantly, PML bodies have been described as facilitating the transcription and replication of doublestranded DNA viral genomes (reviewed in (104)).

EB2/SM has been found to interact with and to induce the expression of Sp110b (105) which has been shown to act as a transcriptional repressor of retinoic acid receptor alpha (106). The interaction between EB2/SM and Sp110b was first observed in a yeast two-hybrid screen and confirmed by co-immunoprecipitation from transfected HeLa cells. In transient expression assays, it was shown that Sp110b had no effect on the expression of intronless heterologous reporter genes, but enhanced EB2/SMmediated activation of the target genes. The effect was post-transcriptional, and $\mathrm{Sp} 110 \mathrm{~b}$ prolonged the half-life of a target intronless heterologous mRNA in the presence of EB2/SM. It was further shown by transient expression assays, that EB2/SM induced the expression of Sp110b in both B lymphocytes and epithelial cells, and that Sp110b was induced during EBV replication in Burkitt's lymphoma cells and gastric epithelial cells. Finally, siRNA partial inhibition of $\mathrm{Sp} 110 \mathrm{~b}$ expression modestly but clearly decreased the expression of one EBV gene, the DNA polymerase processivity factor BMRF1, in EBV-infected B cells in which the lytic cycle was induced by TPA + butyrate. Taken together, these results suggest that Sp110b stabilizes some EBV mRNAs by interacting with EB2, leading to enhanced EB2-mediated export of these mRNAs in EBV infected cells undergoing lytic replication. However, apart from the BMRF1 mRNA, the Sp110b/EB2 viral mRNA targets have not as yet been defined.

\section{PERSPECTIVES}

Although it is now well documented that EB2 has the properties of an RNA export factor, the final proof that EB2 is an RNA export factor would be to inject EB2 into the nucleus of Xenopus laevis oocytes, together with ${ }^{32} \mathrm{P}-$ labeled mRNAs which are known to be exported or not by EB2, in the presence or absence of an excess of the TAP binding RNA motif CTE. In this assay, would EB2 specifically export mRNAs? Several other important questions remain unanswered. There appear to be several NESs in EB2. Where are they precisely located and what are the cellular factors facilitating EB2's shuttling? EB2 binds RNA in vitro and in vivo, but no specific sequence or structure required for binding have been identified. What makes an RNA a target for EB2-mediated mRNA export? Is EB2 recruited co-transcriptionally to the viral mRNPs and if so by which complex? EB2 interacts with several cellular RNA export factors of the TAP/p15 pathway, REF/Aly, OTT1 and perhaps OTT3 (Figure 9). What is the contribution of these factors to the EB2-mediated nuclear export of viral mRNPs ? In particular, which EBV mRNAs are exported in $293_{\mathrm{BMLF} 1-\mathrm{KO}}$ cells expressing EB1 and EB2 with the regions interacting with REF/TAP, OTT3 and/or OTT1 deleted? The three-dimensional structure of EB2 or EB2 sub-domains should be established alone or in association with RNA or with the SPOC domain of OTT3 and OTT1. How does the phosphorylation of EB2 on serines 55, 56 and 57 control its function and how is this phosphorylation itself regulated? Is docking of CK2 essential for EB2 phosphorylation? Does EB2-bound CK2 phosphorylate viral and/or cellular proteins? Last but not least, why is EB2 essential for the nuclear export of just some viral mRNPs, and why can't its function be transcomplemented by HSV-1 ICP27 or CMV UL69? These are challenging studies for the future.

\section{ACKNOWLEDGMENTS}

We thank Dr R. Buckland for reading the manuscript. Some of the work presented in this review was supported by INSERM and grants from the Association pour la Recherche contre le Cancer (ARC 3420 to A. S.) and the Agence Nationale de la Recherche (RPV06120CSA to E.M.) and Lyonbiopôle. A. S. and E. M. are CNRS scientists. H.G. is an INSERM scientist.

\section{REFERENCES}

1. G. Henle, W. Henle and V. Diehl: Relation of Burkitt's tumor-associated herpes type virus to infectious mononucleosis. Proc Natl Acad Sci U S A 59, 94-101 (1968) 
2. G. J. Babcock, L. L. Decker, M. Volk and D. A. ThorleyLawson: EBV persistence in memory $\mathrm{B}$ cells in vivo. Immunity 9, 395-404 (1998)

3. E. D. Kieff and A. B. Rickinson: Epstein-Barr Virus and its replication. In: Fields Virology Fifth Edition. Eds: D. M. Knipe and P. M. Howley, Wolters KLuwer, Lippincot Williams \& Wilkins, Philadelphia (2007)

4. M. P. Thompson and R. Kurzrock: Epstein-Barr virus and cancer. Clin Cancer Res 10, 803-821 (2004)

5. L. G. Labrecque, D. M. Barnes, I. S. Fentiman and B. E. Griffin: Epstein-Barr virus in epithelial cell tumors: a breast cancer study. Cancer Res 55, 39-45 (1995)

6. Y. A. Luqmani and S. Shousha: Presence of Epstein-Barr virus in breast carcinoma. Int J Oncol 6, 899-903 (1995)

7. M. Bonnet, J. M. Guinebretiere, E. Kremmer, V. Grunewald, E. Benhamou, G. Contesso and I. Joab: Detection of Epstein-Barr virus in invasive breast cancers. J Natl Cancer Inst 91, 1376-1381 (1999)

8. P. Gerber, S. Lucas, M. Nonoyama, E. Perlin and L. I. Goldstein: Oral excretion of Epstein-Barr viruses by healthy subjects and patients with infectious mononucleosis. Lancet 2, 988-989 (1972)

9. D. M. Walling, A. J. Ray, J. E. Nichols, C. M. Flaitz and C. M. Nichols: Epstein-Barr virus infection of Langerhans cells precursors as a mechanism of oral epithelial entry, persistence, and reactivation. J Virol 81, 7249-7268 (2007)

10. S. Tugizov, R. Herrera, P. Veluppillai, J. Greenspan, D. Greenspan and J. M. Palefsky: Epstein-Barr virus (EBV)infected monocytes facilitate dissemination of EBV within mucosal epithelium. $J$ Virol 81, 5484-5496 (2007)

11. A. B. Rickinson, J. E. Jarvis, D. H. Crawford and M. A. Epstein: Observations on the type of infection by EpsteinBarr virus in peripheral lymphoid cells of patients with infectious mononucleosis. Int J Cancer 14, 704-715 (1974)

12. J. M. Timms, A. Bell, J. R. Flavell, P. G. Murray, A. B. Rickinson, A. Traverse-Glehen, F. Berger and H. J. Delecluse: Target cells of Epstein-Barr virus (EBV) positive post-transplant lymphoproliferative disease: similarities to EBV-poditive Hodgkin's lymphoma. Lancet 361, 217-223 (2003)

13. G. K. Hong, M. L. Gulley, W. Feng, H. J. Delecluse, E. Holley-Guthrie and S. C. Kenney: Epstein-Barr virus lytic infection contributes to lymphoproliferative disease in a SCID mouse model. J Virol 79, 13993-14003 (2005)

14. D. H. Crawford and I. Ando: EBV virus induction is associated with B-cell maturation. Immunology 59, 405-409 (1986)
15. L. L. Laichalk and D. A. Thorley-Lawson: Terminal differentiation into plasma cells initiates the replicative cycle of Epstein-Barr virus in vivo. J Virol 79, 1296-1307 (2005)

16. H. Zur Hausen, F. J. O'Neil, U. K. Freese and E. Hecker: Persisting oncogenic herpesvirus induced by the tumor promoter TPA. Nature 27, 373-375. (1978)

17. K. Takada and Y. Ono: Synchronous and sequential activation of latently infected Epstein-Barr virus genomes. $J$ Virol 63, 445-449 (1989)

18. H. Fahmi, C. Cochet, Z. Hmama, P. Opolon and I. Joab: Transforming growth factor beta 1 stimulates expression of the Epstein-Barr virus BZLF1 immediate early gene product ZEBRA by an indirect mechanism which requires the MAP kinase pathway. J Virol 74, 5810-5818 (2000)

19. A. Chevallier-Greco, E. Manet, P. Chavrier, C. Mosnier, J. Daillie and A. Sergeant: Both Epstein-Barr virus (EBV) encoded trans-acting factors, EB1 and EB2, are required to activate transcription from an EBV early promoter. EMBO J 5, 3243-3249. (1986)

20. E. Grogan, H. Jenson, J. Countryman, L. Heston, L. Gradoville and G. Miller: Transfection of a rearranged viral DNA fragment, WZhet, stably converts latent Epstein-Barr viral infection to productive infection in lymphoid cells. Proc Natl Acad Sci U S A 84, 1332-1336 (1987)

21. J. M. Hardwick, P. M. Lieberman and D. Hayward: A new Epstein-Barr virus transactivator, $R$, induces expression of a cytoplasmic early antigen. $J$ Virol 62,2274 2284 (1988)

22. A. B. Rickinson and E. D. Kieff: Epstein-barr virus. In: Fields Virology Fifth Edition. Eds: D. M. Knipe and P. M. Howley, Wolters Kluwer, Lippincot Williams and Wilkins, Philadelphia (2007)

23. E. D. Fixman, G. S. Hayward and S. D. Hayward: Trans-acting requirements for replication of Epstein-Barr virus ori-Lyt. J Virol 66, 5030-5039 (1992)

24. I. D. Cook, F. Shanahan and P. J. Farrell: Epstein Barr virus SM protein. Virology 205, 217-227 (1994)

25. J. Sample, A. Tanaka, G. Lancz and M. Nonoyama: Identification of Epstein-Barr virus genes expressed during the early phase of virus replication and during lymphocytes immortalization. J Virol 139, 1-10 (1984)

26. J. Sample, G. Lancz and M. Nonoyama: Mapping of genes in BamH I frament $M$ of Epstein-Barr virus DNA that may determine the fate of viral infection. $J$ Virol 57, 145-154 (1986)

27. M. Buisson, E. Manet, M. C. Biemont, H. Gruffat, B. Durand and A. Sergeant: The Epstein-Barr Virus (EBV) early protein EB2 is a posttranscriptional activator 
expressed under the control of EBV transcription factors EB1 and R. J Virol 63, 5276-5284. (1989)

28. H. Gruffat, N. Duran, M. Buisson, F. Wild, R. Buckland and A. Sergeant: Characterization of an Rbinding site mediating the R-induced activation of the Epstein-Barr virus BMLF1 promoter. $J$ Virol 66, 46-52. (1992)

29. K. M. Wong and A. J. Levine: Identification and mapping of Epstein-Barr virus early antigens and demonstration of a viral gene activator that functions in trans. J Virol. 60, 149-156 (1986)

30. P. M. Lieberman, P. O'Hare, G. S. Hayward and S. D. Hayward: Promiscous trans activation of gene expression by an Epstein-Barr virus-encoded early nuclear protein. $J$ Virol 60, 140-148 (1986)

31. S. Kenney, J. Kamine, E. Holley-Guthrie, E. C. Mar, J. C. Lin, D. Markovitz and J. Pagano: The Epstein-Barr virus immediate-early gene product, BMLF1, acts in trans by a posttranscriptional mechanism which is reporter gene dependent. J Virol 63, 3870-3877 (1989)

32. O. J. Semmes, L. Chen, R. Sarisky, Z. Gao, L. Zhong and S. D. Hayward: Mta has properties of an RNA export protein and increases cytoplasmic accumulation of EpsteinBarr virus replication gene mRNA. J Virol 72, 9526-9534 (1998)

33. H. Fried and U. Kutay: Nucleocytoplasmic transport: taking an inventory. Cell Mol Life Sci 60, 159-130 (2003)

34. E. Hiriart, L. Bardouillet, E. Manet, H. Gruffat, F. Penin, R. Montserret, G. Farjot and A. Sergeant: A region of the Epstein-Barr Virus (EBV) mRNA export factor EB2 containing an arginine-rich motif mediates direct binding to RNA. J Biol Chem 278, 37790-37798 (2003)

35. U. Fischer, J. Huber, W. C. Boelens, I. W. Mattaj and R. Luhrmann: The HIV-Rev activation domain is a nuclear export signal that accesses an export pathway used by specific cellular RNAs. Cell 82, 475-483 (1995)

36. B. Ossareh-Nazari, F. Bachelerie and C. Dargemont: Evidence for a role of CRM1 in signal-mediated nuclear protein export. Science 278, 141-144 (1997)

37. M. Fornerod, M. Ohno, M. Yoshida and I. W. Mattaj: Crm-1 is an export receptor for leucine rich nuclear export signals. Cell 90, 1051-1060 (1997a)

38. K. Stade, C. S. Ford, C. Guthrie, and K. Weis, Exportin1 (Crm1p) is an essential nuclear export factor. Cell 90, 1041-1050 (1997)

39. M. Fukuda, S. Asano, T. Nakamura, M. Adachi, M. Yoshida, M. Yanagida and E. Nishida: CRM1-1 is responsible for intracellular transport mediated by the nuclear export signal. Nature 390, 308-311 (1997)
40. M. S. Rodriguez, C. Dargemont and F. Stutz: Nuclear export of RNA. Biol Cell 96, 639-655 (2004)

41. M. Malim, D. F. McCarn, L. S. Tiley and B. R. Cullen: Mutational definition of the human immunodeficiency type 1 Rev activation domain. $J$ Virol 65, 4248-4254 (1991)

42. S. M. Boyle, V. Ruvolo, A. K. Gupta and S. Swaminathan: Association with the cellular export receptor CRM-1 mediates function and intracellular localization of Epstein-Barr Virus SM protein, a regulator of gene expression. J Virol 73, 6872-6881 (1999)

43. L. Chen, G. Liao, M. Fujimoro, O. J. Semmes and S. D. Hayward: Properties of two EBV Mta nuclear export signal sequences. Virology 288, 119-128 (2001)

44. G. Farjot, M. Buisson, M. Duc Dodon, L. Gazzolo, A. Sergeant and I. Mikaelian: Epstein-Barr virus EB2 protein exports unspliced RNA via a crm-1 independent pathway. $J$ Virol 74, 6068-6076 (2000)

45. B. Wollf, J. J. Sanglier and Y. Wang: Leptomycin B is an inhibitor of nuclear export: inhibition of nucleocytoplasmic translocation of the human immunodeficiency virus type 1 (HIV-1) Rev protein and Rev-dependent mRNA. Chem Biol 4, 139-147 (1997)

46. E. Hiriart, G. Farjot, H. Gruffat, M. V. Nguyen, A. P. Sergeant and E. Manet: A novel NES and a REF interaction domain both promote mRNA export by the Epstein-Barr Virus EB2 protein. J Biol Chem 278, 335-342 (2003)

47. M. D. Koffa, J. B. Clements, E. Izaurralde, S. Wadd, S. A. Wilson, I. W. Mattaj and S. Kuersten: Herpes simplex virus ICP27 protein provides viral mRNAs with access to the cellular mRNA export pathway. EMBO J 20, 57695778 (2001)

48. Y. Huang and J. A. Steitz: Splicing factors SRp20 and 9G8 promote the nucleocytoplasmic export of mRNA. Mol Cell 7, 899-905 (2001)

49. P. Grüter, C. Tabernero, C. von Kobbe, C. Schmitt, C. Saavedra, A. Bachi, M. Wilm, B. K. Felber and E. Izaurralde: TAP, the human homolog of Mex67p, mediates CTE-dependent RNA export from the nucleus. Mol Cell 1, 649-659 (1998)

50. M. H. Malim, J. Hauber, S. Y. Le, J. V. Maizel and B. R. Cullen: The HIV-1 Rev transactivator acts through a structured target sequence to activate nuclear export of unspliced viral mRNA. Nature 338, 254-257 (1989)

51. S. Lindtner, Z. A.S., H. Uranishi, J. Bear, V. Kulkarni, S. Smulevitch, M. Samiotaki, G. Panayotou, B. K. Felber and G. N. Pavlakis: RNA-binding motif protein 15 binds to the RNA transport element RTE and provides a direct link to the NXF1 export pathway. J Biol Chem 281, 3691536928 (2006) 
52. H. Le Hir, E. Izaurralde, L. E. Maquat and M. J. Moore: The spliceosome deposits multiple proteins 20-24 nucleotides upstream of mRNA exon-exon junctions. EMBO J 19, 6860-6869 (2000)

53. H. Le Hir, D. Gatfield, E. Izaurralde and M. Moore: The exon-exon junction complex provides a binding platform for factors involved in mRNA export and NMD. EMBO J 20, p.4987-4997 (2001)

54. S. Masuda, R. Das, H. Cheng, E. Hurt, N. Dorman and R. Reed: Recruitment of the human TREX complex to mRNA during splicing. Genes Dev 19, 1512-1517 (2005)

55. H. Cheng, K. Dufu, C. Lee, J. L. Hsu, A. Dias and R. Reed: Human mRNA export machinery recruited to the $5^{\prime}$ end of mRNA. Cell 127, 1389-1400 (2006)

56. D. Lazinski, E. Grzadzielska and A. Das: Sequencespecific recognition of RNA hairpins by bacteriophage antiterminators requires a conserved arginine-rich motif. Cell 59, 207-218 (1989)

57. R. Tan and A. D. Frankel: Structural variety of arginine-rich RNA-binding peptides. Proc Natl Acad Sci U $S A$ 92, 5282-5286 (1995)

58. L. Chen and A. D. Frankel: A peptide interaction in the major groove of RNA resembles protein interactions in the minor groove of DNA. Proc Natl Acad Sci U S A 92, 50775081 (1995)

59. M. Zuker, D. H. Mathews and D. H. Turner: Algorithms and thermodynamics for RNA secondary structure prediction: A practical guide. Kluwer Academic (1999)

60. R. J. Roller and B. Roizman: The herpes simplex virus Us11 open reading frame encodes a sequence-specific RNA-binding protein. J Virol 64, 3463-3470 (1990)

61. M. Buisson, F. Hans, I. Kusters, N. Duran and A. Sergeant: The C-terminal region but not the Arg-X-Pro repeat of Epstein-Barr virus protein EB2 is required for its effect on RNA splicing and transport. $J$ Virol 73, 40904100 (1999)

62. V. Ruvolo, A. K. Gupta and S. Swaminathan: EpsteinBarr SM protein interacts with mRNA in vivo and mediates a gene-specific increase in cytoplasmic mRNA. J Virol 75, 6033-6041 (2001)

63. A. Aguilera: Cotranscriptional mRNP assembly: from the DNA to the nuclear pore. Curr Opin Cell Biol 17, 242$250(2005)$

64. R. Das, J. Yuan, Z. Zhang, M. P. Gygi, A. R. Krainer, S. P. Gygi and R. Reed: SR proteins function in coupling RNAP II transcription to pre-mRNA splicing. Mol Cell 26, 867-881 (2007)
65. Y. G. Chen, R. E. Moore, H. Y. Ge, M. K. Young, T. D. Lee and S. W. Stevens: Proteomic analysis of in vivoassembled pre-mRNA splicing complexes expands the catalog of participating factors. Nucleic Acids Res 35, 3928-3944 (2007)

66. Y. Huang, R. Gattoni, J. Stevenin and J. A. Steitz: SR splicing factors serve as adapter proteins for TAPdependent mRNA export. Mol Cell 11, 837-843 (2003)

67. T. Nojima, T. Hirose, H. Kimura and M. Hagiwara: The interaction between cap-binding complex and RNA export factor is required for intronless mRNA export. $\mathrm{J} \mathrm{Biol} \mathrm{Chem}$ 282, 15645-15651 (2007)

68. E. Hiriart, H. Gruffat, M. Buisson, I. Mikaelian, S. Keppler, P. Meresse, T. Mercher, O. A. Bernard, A. Sergeant and E. Manet: Interaction of the Epstein-Barr virus mRNA export factor EB2 with Human Spen proteins SHARP, OTT1 and a novel member of the family, OTT3, links Spen proteins with splicing regulation and mRNA export. J Biol Chem 280, 36935-36945 (2005)

69. M. Ariyoshi and W. R. Schwabe: A conserved structural motif reveals the essential transcriptional repression function of Spen proteins and their role in development signaling. Genes Dev 17, 1909-1920 (2003)

70. V. Ruvolo, E. Wang, S. Boyle and S. Swaminathan: The Epstein-Barr virus nuclear protein SM is both a posttranscriptional inhibitor and activator of gene expression. Proc Natl Acad Sci U S A 95, 8852-8857. (1998)

71. V. Ruvolo, L. Navarro, C. E. Sample, M. David, S. Sung and S. Swaminathan: The Epstein-Barr virus SM protein induces STAT1 and interferon-stimulated gene expression. J Virol 77, 3690-3701 (2003)

72. T. J. Hope, B. L. Bond, D. McDonald, N. P. Klein and T. G. Parslow: Effector domains of Human immunodeficiency virus type $1 \mathrm{Rev}$ and human T-cell leukaemia virus type I Rex are functionally interchangeable and share an essential peptide motif. J Virol 65, 6001-6007 (1991)

73. A. Staffa and A. Cochrane: The tat/rev intron of human immundeficiency virus 1 is inefficiently spliced because of suboptimal signals in the 3' splice site. J Virol 68, 30713079 (1994)

74. R. Yi, H. P. Bogerd, H. L. Wiegand and B. R. Cullen: Both Ran and importins have the ability to function as nuclear mRNA export factors. $R N A 8,180-187$ (2002)

75. R. Treisman, S. H. Orkin and T. Maniatis: Specific transcription and RNA splicing defects in five cloned betathalassaemia genes. Nature 302, 591-596 (1983)

76. J. F. Caceres, S. Stamm, D. H. Helfman and A. R. Krainer: Regulation of alternative splicing in vivo by overexpression of antagonistic splicing factors. Science 265, 1706-1709. (1994) 
77. J. Batisse, E. Manet, J. Middeldorp, A. Sergeant and H. Gruffat: The Epstein-Barr virus mRNA export factor EB2 is essential for intranuclear capsid assembly and production of gp350. J Virol 79, 14102-14111 (2005)

78. V. Ruvolo, L. Sun, K. Howard, S. Sung, H. J. Delecluse, W. Hammerschmidt and S. Swaminathan: Functional analysis of Epstein-Barr virus SM protein: identification of amino acids essential for structure, transactivation, splicing inhibition, and virion production. $J$ Virol 340-352 (2004)

79. S. C. Silver Key, T. Yoshizaki and J. Pagano: The Epstein-Barr virus (EBV) SM protein enhances pre-mRNA processing of the EBV DNA polymerase transcript. $J$ Virol 72, 8485-8492 (1998)

80. H. Gruffat, J. Batisse, D. Pich, B. Neuhierl, E. Manet, W. Hammerschmidt and A. Sergeant: Epstein-Barr virus mRNA export factor EB2 is essential for production of infectious virus. $J$ Virol 76, 9635-9644 (2002)

81. Z. Han, E. Marendy, Y. Wang, J. Yuan, J. T. Sample and S. Swaminathan: Multiple roles of Epstein Barr virus SM protein in lytic replication. $J$ Virol 81, 4058-4069 (2007)

82. M. Hummel, D. A. Thorley-Lawson and E. Kieff: An Epstein-Barr virus DNA fragment encodes messages for the two major envelope glycoproteins (gp350/300 and gp220/200). J Virol 49, 413-417 (1984)

83. R. M. Sandri-Goldin: ICP 27 mediates HSV RNA export by shuttling through a leucine-rich nuclear export signal and binding viral intronless RNAs through an RGG motif. Genes Dev 12, 868-879 (1998)

84. I.-H. Chen, K. S. Sciabica and R. M. Sandri-Goldin: ICP27 interacts with the export factor Aly/REF to direct herpes simplex virus type 1 intronless RNAs to the TAP export pathway. J Virol 76, 12877-12889 (2002)

85. P. Lischka, Z. Toth, M. Thomas, R. Mueller and T. Stamminger: The UL69 transactivator protein of human cytomegalovirus interacts with DEXD/H-Box RNA helicase UAP56 to promote cytoplasmic accumulation of unspliced RNA. Mol Cell Biol 26, 1631-1643 (2006)

86. P. Malik, D. Blackbourn and B. Clements: The evolutionary conserved Kaposi's sarcoma-associated herpesvirus ORF57 protein interacts with REF and acts as an RNA export factor. $J$ Biol Chem 279, 33001-33011 (2004)

87. A. M. McCarthy, L. McMahan and P. A. Schaffer: Herpes simplex virus type I ICP27 deletion mutant exhibits altered patterns of transcription and are DNA deficient. $J$ Virol 63, p.18-27 (1989)

88. Z. Han and S. Swaminathan: Kaposi's sarcomaassociated herpesvirus lytic gene ORF57 is essential for infectious virion production. J Virol 80, 5251-5260 (2006)
89. P. Lischka, O. Rosorius, E. Trommer and T. Stamminger: A novel transferable nuclear export signal mediates CRM1-independent nucleocytoplasmic shuttling of the human cytomegalovirus transactivator protein pUL69. EMBO J 20, 7271-7283 (2001)

90. A. Pearson, D. M. Knipe and D. M. Coen: ICP27 selectively regulates the cytoplasmic localization of a subset of viral transcripts in Herpes Simplex Virus type 1infected cells. $J$ Virol 78, 23-32 (2004)

91. J. Kirshner, D. Lukac, J. Chang and D. Ganem: Kaposi's sarcoma-associated herpesvirus open reading frame 57 encodes a posttranscriptional regulator with multiple distinct activities. J Virol 74, 3586-3597 (2000)

92. M. Winkler, T. aus Dem Siepen and T. Stamminger: Functional interaction between pleiotropic transactivator pUL69 of human cytomegalovirus and the human homolog of yeast chromatin regulatory protein SPT6. J Virol 74, 8053-8064 (2000)

93. C. D. Kaplan, L. Laprade and F. Winston: Transcription elongation factors repress transcription initiation from cryptic sites. Science 301, 1096-1099 (2003)

94. M. W. Adkins and J. K. Tylet: Transcriptional activators are dispensable for transcription in the absence of Spt6-mediated chromatin reassembly of promoter regions. Mol Cell 21, 405-416 (2006)

95. S. M. Yoh, H. Cho, L. Pickle, R. M. Evans and K. A. Jones: The Spt6 SH2 domain binds Ser2-P RNAII to direct Iws1-dependent splicing and export. Genes Dev 15, 160174 (2007)

96. K. S. Sciabica, Q. J. Dai and R. M. Sandri-Goldin: ICP27 interacts with SRPK1 to mediate HSV spicing inhibition by altering SR protein phosphorylation. EMBO J 22, 1608-1619 (2003)

97. Z. Toth, P. Lischka and T. Stamminger: RNA-binding of the human cytomegalovirus transactivator protein UL69, mediated by arginine-rich motifs, is not required for nuclear export of unspliced RNA. Nucleic Acids Res 34, 1237-1249 (2006)

98. J. L. Boyer, S. Swaminathan and S. J. Silverstein: The Epstein-Barr virus SM protein is functionally similar to ICP27 from herpes simplex virus in viral infections. $J$ Virol 76, 9420-9433 (2002)

99. K. M. Wong and A. J. Levine: Characterization of proteins encoded by the Epstein-Barr virus transactivator gene BMLF1. Virology 168, 101-111 (1989)

100. L. A. Pinna: Protein kinase CK2: a challenge to canons. J Cell Sci 115, 3873-3878 (2002)

101. O. Filhol, A. Nueda, V. Martel, D. Gerber-Scokaert, M. J. Benitez, C. Souchiez, Y. Saoudi and C. Cochet: Livecell fluorescence imaging reveals the dynamic of protein 
The EBV early protein EB2 is an RNA export factor

kinase CK2 individual subunits. Mol Cell Biol 23, 975-987 (2003)

102. C. Medina-Palazon, H. Gruffat, F. Mure, O. Filhol, V. Vingtdeux-Didier, H. Drobecq, C. Cochet, N. Sergeant, A. Sergeant and E. Manet: Protein kinase CK2 phosphorylation of EB2 regulates its function in the production of EBV infectious particles. $J$ Virol 81, in press (2007)

103. D. B. Bloch, A. Nakajima, T. Gulik, J. Chiche, D. Orth, S. M. de la Monte and K. D. Bloch: Sp110 localizes to the PML-Sp100 Nuclear body and may function as a nuclear hormone receptor transcriptional coactivator. $\mathrm{Mol}$ Biol Cell 20, 6138-6146 (2000)

104. R. W. Ching, G. Dellaire, C. H. Eskiw and D. P. Bazett-Jones: PML bodies: a meeting place for genomic loci? J Cell Sci 118, 847-854 (2005)

105. J. Nicewonger, G. Suck, D. Bloch and S. Swaminathan: Epstein-Barr Virus (EBV) SM protein induces and recruits cellular Sp110b to stabilize mRNAs and enhance EBV lytic gene expression. J Virol 78, 94129422 (2004)

106. K. Watashi, M. Hijikata, A. Tagawa, T. Doi, H. Marusawa and K. Shimotohno: Modulation of retinoid signaling by a cytoplasmic viral protein via sequestration of $\mathrm{Sp} 110 \mathrm{~b}$, a potent transcriptional corepressor of retinoic acid receptor, from the nucleus. Mol Biol Cell 23, 7498-7509 (2003)

107. O. de Jesus, P. A. Smith, L. C. Spencer, C. E. Karsteg, H. H. Noiller, D. Huang and P. J. Farrell: Updated EpsteinBarr virus (EBV) DNA sequence and analysis of a promoter for the BART (CST, BARF0) RNAs of EBV. $J$ Gen Virol 84, 1443-1450 (2003)

Abbreviations: ARM: Arginine Rich Motif, AP-1: Activating Protein 1, CAT: Chloramphenicol Acetyl Transferase, CRM1: Chromosomal Maintenance Region 1, EJC: Exon Junction Complex, GST: Glutathione-Stranferase, NPC: Nuclear Pore Complex, RBD: RNABinding Domain, RRM: RNA Recognition Motif, RXP: Argine-X-Proline

Key Words: Epstein Barr Virus, Lytic Cycle, Early Protein EB2, RNA export, RNA-Binding, Protein Kinase CK2, Review

Send correspondence to: Dr Alain Sergeant, INSERM U758, ENS-Lyon, 46 allee d'Italie, 69364 Lyon Cedex 07, France, Tel: 3347272 8177, Fax: 33472728137, E-mail: alain.sergeant@ens-lyon.fr 